\title{
Karakterizacija mikroplastike u sedimentu plaže Prapratno
}

\author{
M. Erceg, ${ }^{a^{*}}$ P. Tutman, ${ }^{b}$ D. Bojanić Varezićb i A. Bobanovića \\ a Kemijsko-tehnološki fakultet, Ruđera Boškovića 35, 21 000, Split, Hrvatska \\ b Institut za Oceanografiju i Ribarstvo, Šetalište Ivana Meštrovića 63, 21 000, Split, Hrvatska
}

Ovo djelo je dano na korištenje pod Creative Commons Attribution 4.0 (n)

\begin{abstract}
Sažetak
Mikroplastika predstavlja ozbiljan problem u morskom i priobalnom okolišu. Analiziran je uzorak mikroplastike iz sedimenta plaže Prapratno na poluotoku Pelješcu, Hrvatska. Uzorkovanje i laboratorijsko odvajanje provedeni su prema DeFishGear protokolu. Svaki ispitak svrstan je u određenu kategoriju te je svakom određena masa, boja, prozirnost, maksimalna dimenzija i površina. Identifikacija je provedena infracrvenom spektroskopijom (FTIR) - HATR tehnikom. Otpad s plaže Prapratno sastoji se uglavnom od polietilena te, u manjem udjelu, od polistirena i polipropilena.
\end{abstract}

\section{Ključne riječi}

Mikroplastika, kategorije otpada, sediment, infracrvena spektroskopija, Prapratno

\section{Uvod}

Plastika je materijal čiji je osnovni sastojak tvar visoke molekulske mase i koji se pri potrebnoj smičnoj viskoznosti može praoblikovati. ${ }^{1}$ Plastika je danas neizostavan dio svakodnevnog života i dokazano ima ključnu ulogu za održivo gospodarstvo. ${ }^{2}$ Zbog svoje prilagodljivosti novopostavljenim uvjetima u proizvodnji i preradi, dobrom omjeru cijene i kvalitete, trajnosti, niskoj gustoći i drugim dobrim svojstvima, plastika kao materijal značajno doprinosi efikasnijoj uporabi resursa. Današnje potrošačko društvo podrazumijeva sve veću proizvodnju i potrošnju svih vrsta materijala, pa tako i plastike. Može se kazati da se proizvodi od plastike zbog svoje svestranosti i niske cijene upotrebljavaju i više nego što je potrebno te zasigurno treba poraditi na potrošačkim navikama. Svjetska proizvodnja plastike u 2017. godini dosegla je gotovo 350 milijuna tona. ${ }^{2}$ Podatci za Europsku uniju zajedno s Norveškom i Švicarskom pokazuju da 39,7 \% plastike otpada na ambalažu, 19,8 \% na primjenu u građevinarstvu, 10,1 \% na automobilsku industriju, 6,2\% na električnu i elektroničku industriju, 4,1\% na kućanstva, sport i rekreaciju, 3,4 \% na poljoprivredu te $16,7 \%$ na sva ostala područja. ${ }^{2}$ Najviše se upotrebljava polipropilen (PP) 19,3\%, polietilen niske gustoće (PE-LD) i linearni polietilen niske gustoće (PE-LLD) 17,5 \%, polietilen visoke gustoće (PE-HD) i polietilen srednje gustoće (PE-MD) 12,3\%, poli(vinil-klorid) (PVC) 10,2 \%, poliuretani (PUR) 7,7 \%, poli(etilen-tereftalat) (PET) 7,4 \%, polistiren (PS) i pjenasti polistiren (PS-E) 6,6 \% i 19,0\% ostala plastika (uglavnom akrilonitril/butadien/stiren - ABS, poli(butadien-tereftalat) - PBT, polikarbonat - PC, poli(metilmetakrilat) - PMMA i poli(tetrafluoretilen) - PTFE).

Problem može nastati nakon završetka uporabe plastičnih proizvoda, tj. kada oni postanu otpad ako se njime ispravno ne gospodari. Neki plastični proizvodi koriste se jed-

*Autor za dopisivanje: prof. dr. sc. Matko Erceg

e-pošta: matko.erceg@ktf-split.hr

Rad je prezentiran na VII. hrvatskom simpoziju o kemiji i tehnologiji makromolekula 2019. nokratno, neki imaju vijek uporabe kraći od godine dana, neki primjerice 10 godina, a neki i više od 50 godina. Zato je vrlo važno shvatiti da plastični proizvodi imaju vrlo različite životne cikluse te da količina plastike koja se godišnje stavi na tržište ne odgovara godišnjoj količini otpada. Plastični se otpad može organizirano sakupljati i oporabiti (mehanički, kemijski ili energijski) ili nekontrolirano odbacivati u okoliš. Najnoviji podatci za Europsku uniju, koja je predvodnik u oporabi plastike, pokazuju da je tek od 2016. količina sakupljenog plastičnog otpada veća od količine koja završi na odlagalištima. ${ }^{2}$ Od sakupljenih 27,1 milijuna tona u 2017. 41,6 \% se energetski oporabi, $31,1 \%$ se materijalno oporabi, a 27,3 \% završi na uređenim odlagalištima otpada. U posljednjih deset godina energetska oporaba plastičnog otpada porasla je za $61,0 \%$, materijalna za $79,0 \%$, dok se odlaganje smanjilo za 43,0 \%. ${ }^{2}$ Razlog takvom trendu je činjenica da je plastični otpad vrlo vrijedna sekundarna sirovina. Međutim, velika većina država nema razvijen funkcionalan način zbrinjavanja plastičnog otpada i stoga on završi u okolišu. Tu se trajnost plastike, kao jedno od njezinih osnovnih prednosti, pretvara u nedostatak budući da nije biorazgradljiva u okolišu. Ipak, plastika u okolišu nakon odbacivanja podliježe drugim procesima razgradnje. Plastika izložena utjecaju atmosferilija (sunca, kiše, vjetra, ozona) i atmosferskih onečišćenja postaje krhka, lomi se, usitnjava i postaje dio okoline u kojoj se nalazi (tlo, jezera, rijeke, mora). Kada čestice plastike postanu dovoljno malih dimenzija, kategoriziraju se kao mikroplastika. Mikroplastika je naziv za čestice plastike promjera manjega od 5 milimetara, ${ }^{3}$ a može biti primarna (prisutna u dimenzijama koje odgovaraju mikroplastici od trenutka izrade proizvoda) i sekundarna (nastaje fragmentacijom krupnijih komada plastike uslijed procesa razgradnje tijekom vremena). Čestice mikroplastike predstavljaju ozbiljan problem u morskom okolišu. ${ }^{4}$ Mikroplastični otpad završi u vodenim sustavima isključivo zbog ljudske aktivnosti na kopnu. Mikroplastika može zatvoriti probavni sustav morskih životinja koje ju zamijene za prirodni plijen i tako dođe do njihova uginuća, a zbog malih dimenzija lako ulazi u morske organizme kroz usta ili škrge. 5,6 Međutim, još 
je opasnije svojstvo mikroplastike da na sebe veže toksične spojeve. Oni se nakupljaju i prenose kroz hranidbene lance i naposljetku dolaze do čovjeka. ${ }^{7}$ Da bi se smanjila količina mikroplastike u okolišu, ponajprije je važno smanjiti količinu otpadne plastike koja nekontrolirano dospijeva u okoliš.

Mikroplastika različitih dimenzija zabilježena je u sedimentima plaža diljem svijeta. Institut za oceanografiju i ribarstvo iz Splita u sklopu projekta Sustav upravljanja morskim otpadom u Jadranskoj regiji, DeFishGear (engl. Derelict Fishing Gear Management System in the Adriatic Region) pokrenuo je istraživanje koje se bavi problematikom mikroplastike u Jadranskom moru, pa su i uzorci za analizu u ovom radu dobiveni od Instituta za oceanografiju i ribarstvo iz Splita. Cilj ovog rada bio je analizirati mikroplastični otpad iz sedimenta plaže Prapratno na poluotoku Pelješcu te ukazati na problematiku mikroplastike koja je rastući onečišćivač mora i oceana.

\section{Eksperimentalni dio}

\subsection{Uzorkovanje i razvrstavanje mikroplastike}

Pješčana plaža Prapratno na poluotoku Pelješcu (Hrvatska) odabrana je zbog mogućnosti pristupa tijekom cijele godine i orijentacije prema prevladavajućim vjetrovima, jugu u hladnijem i maestralu u toplijem dijelu godine, čime je povećana vjerojatnost nakupljanja otpada. Uzorkovanje mikroplastike obavljeno je u srpnju 2017. godine prema predloženoj metodologiji. ${ }^{8}$ Uzorci su uzeti iznad zone prskanja valova, i to tri ponovljena uzorka s minimalnim razmakom od $5 \mathrm{~m}$. Replike su raspodijeljene tako da budu reprezentativne za cijelu plažu ili za određeni dio plaže. $\mathrm{Na}$ površinu pijeska postavljen je drveni kvadrat veličine $100 \mathrm{~cm} \times 100 \mathrm{~cm}$ te je metalnom lopaticom sakupljeno gornjih $3-5 \mathrm{~cm}$ pijeska. Pijesak je stavljan u staklenu menzuru kako bi se izračunao volumen uzorkovanog sedimenta te je potom prosijan kroz metalna sita od 4 i
$1 \mathrm{~mm}$. Materijal koji se zadržao na sitima od $4 \mathrm{~mm}$ i $1 \mathrm{~mm}$ odvojeno je pohranjen u papirnate vrećice. Postupak je ponovljen onoliko puta koliko je bilo potrebno za uzorkovanje zadane površine. Ukupno je prosijano 9 l, tj. 17,1 kg sedimenta. U laboratoriju je materijal sa sita od $4 \mathrm{~mm}$ i $1 \mathrm{~mm}$ prebačen u staklene posudice. Sve čestice (umjetni predmeti) veličine 4,1 - $25 \mathrm{~mm}$ (mezootpad) prikupljene na situ veličine $4 \mathrm{~mm}$ kategorizirane su prema popisu morskog otpada naplavljenog na plaži. Svi umjetni predmeti (otpad) veličine $1-4,1 \mathrm{~mm}$ prikupljeni na situ od $1 \mathrm{~mm}$ izdvojeni su pincetom pod stereomikroskopom i pohranjeni u staklene bočice za daljnju analizu.

\subsection{Karakterizacija mikroplastike}

Prije početka rada na karakterizaciji uzorka mikroplastičnog otpada, uzorak je u cijelosti izvagan na analitičkoj vagi Sartorius A 200 S.

Mikroplastični otpad je najprije vizualno razvrstan u kategorije prema EU TG ML Master List. ${ }^{9}$ U dostavljenom uzorku pronađene su sljedeće kategorije mikroplastičnog otpada: fragmenti, peleti, granule, filamenti, filmovi i pjenasti oblici. Primjeri ispitaka po pojedinim kategorijama prikazani su na slici $1(a-f)$.

Nakon razvrstavanja u kategorije utvrđen je broj ispitaka u svakoj kategoriji a zatim je svaki ispitak izvagan na analitičkoj vagi Sartorius A 200 S.

Nakon vaganja pristupilo se određivanju boje te prozirnosti/neprozirnosti svakog ispitka. Prema DeFishGear protokolu mikroplastika se klasificira prema sljedećim bojama: bijela, bistro-krem, crvena, narančasta, plava, crna, siva, smeđa, zelena, ljubičasta, žuta te bež, a prema prozirnosti se klasificira kao prozirna ili neprozirna.

Primjenom Digimizer programa za obradu fotografija svakom ispitku je izračunata maksimalna dimenzija $(\mathrm{mm})$ i površina $\left(\mathrm{mm}^{2}\right)$. Postupak uključuje učitavanje fotografija
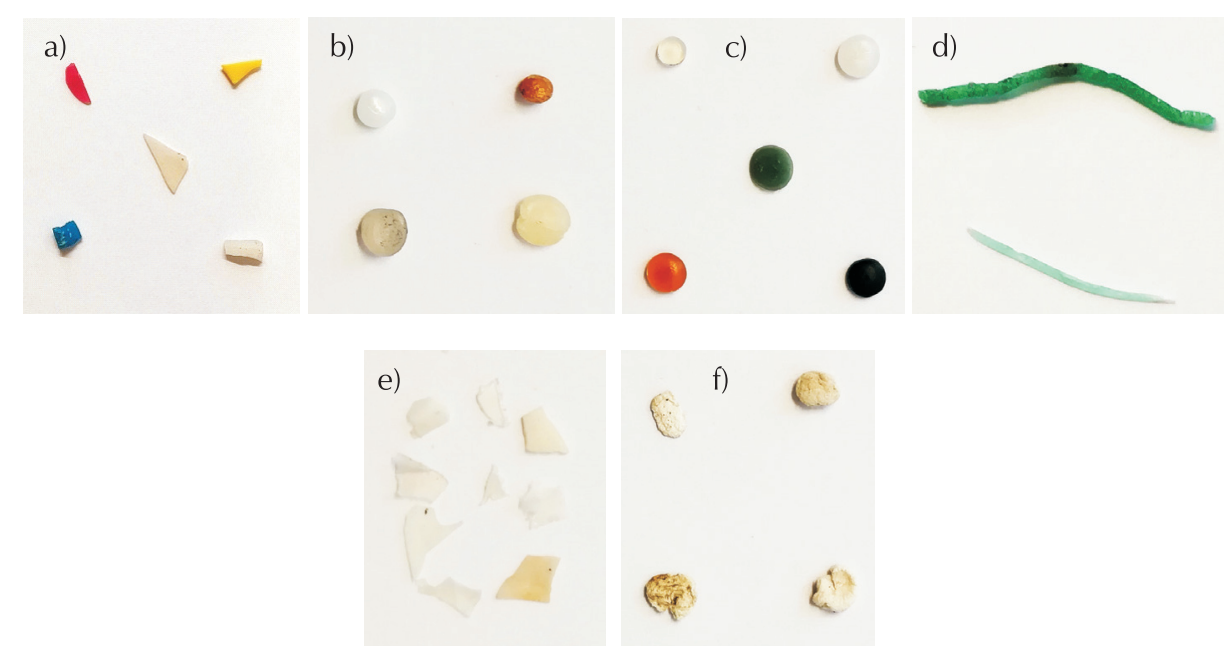

Slika 1 - Kategorije mikroplastičnog otpada iz sedimenta plaže Prapratno: a) fragmenti, b) peleti, c) granule, d) filament, e) filmovi i f) pjenasti oblici

Fig. 1 - Categories of microplastic waste from Prapratno beach sediment: a) fragments, b) pellets, c) granules, d) filaments, e) films, and f) foams 
ispitaka u Digimizer program. Na fotografijama ispitaka se pokretom miša označi cijeli rub svake pojedine čestice uz prethodno zadanu referentnu vrijednost, a program izračuna maksimalnu dimenziju i površinu.

\subsection{Identifikacija mikroplastike primjenom infracrvene spektroskopije}

Identifikacija vrste plastike od koje je izrađen svaki ispitak provedena je primjenom infracrvene spektroskopije s Fourierovom transformacijom (FT-IR) u srednjem području valnih duljina infracrvenog područja. Mjerenja su provedena uporabom FT-IR spektrometra Perkin-Elmer Spectrum One. Za spektroskopiranje uzoraka primijenjena je tehnika HATR (engl. Horizontal Attenuated Total Reflection). Nakon pokretanja računalnog programa snimljen je spektar pozadine (engl. background), odnosno samo kristal ZnSe $\left(45^{\circ}\right)$. Potom se ispitak stavi na ZnSe kristal te pričvrsti pomoću poluge za primjenu sile da se osigura dobar kontakt. Prije spektroskopiranja svaki ispitak obrisan je etilnim alkoholom namočenom krpicom koja ne ostavlja vlakna.

Snimanja su provedena u valnom području od 4000 do $650 \mathrm{~cm}^{-1}$ uz spektralnu rezoluciju $4 \mathrm{~cm}^{-1}$. Svaki ispitak snimljen je deset puta, a dobiveni IR spektar predstavlja njihovu prosječnu vrijednost. U svrhu identifikacije, dobiveni IR spektri uspoređeni su sa spektrima u računalnoj bazi podataka, a na osnovu najbolje podudarnosti identificirana je vrsta plastike od koje je izrađen svaki ispitak.

\section{Rezultati i rasprava}

\subsection{Karakterizacija mikroplastike}

Prije karakterizacije uzorka mikroplastičnog otpada uzorak je u cijelosti izvagan, a ukupna masa iznosila je 0,8700 g.

Rezultati vizualnog razvrstavanja mikroplastičnog otpada u kategorije prema EU TG ML Master List prikazani su na slikama 2 i 3 . Uzorak se sastoji od 116 ispitaka. Rezultati

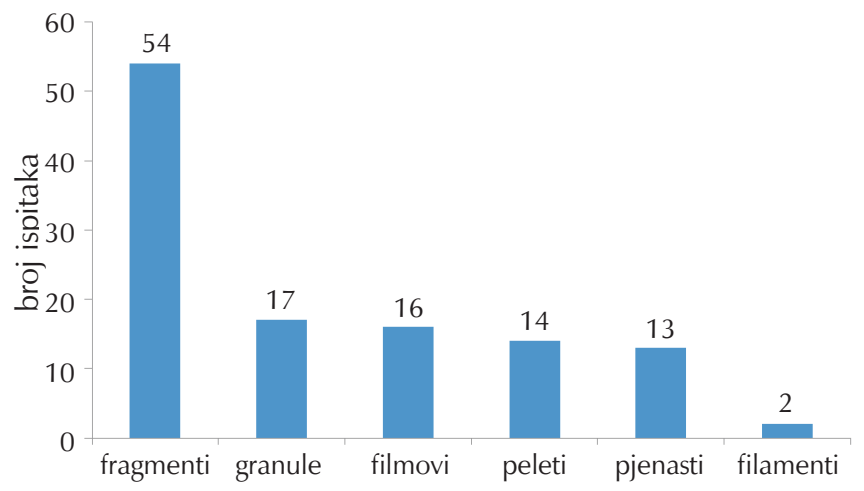

Slika 2 - Broj ispitaka u pojedinoj kategoriji mikroplastičnog otpada iz sedimenta plaže Prapratno

Fig. 2 - Number of specimens in each microplastic waste category from Prapratno Beach sediment

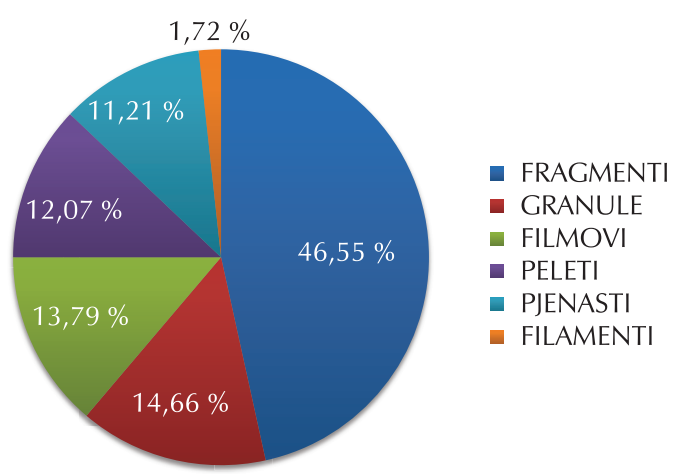

Slika 3 - Brojčani udjeli ispitaka u pojedinoj kategoriji mikroplastičnog otpada iz sedimenta plaže Prapratno

Fig. 3 -Numerical fraction of each category of microplastic waste from Prapratno Beach sediment

pokazuju da su fragmenti najzastupljenija kategorija mikroplastičnog otpada iz sedimenta plaže Prapratno, granule, filmovi, peleti i pjenasti ispitci zastupljeni su u približno istom broju, dok su filamenti najmanje zastupljena kategorija. Oko 27 \% ispitaka (i brojčano i po masi) čine granule i peleti, dakle neprerađeni plastični materijal koji je završio kao otpad u sedimentu plaže Prapratno.

Nakon razvrstavanja u kategorije svaki ispitak je izvagan na analitičkoj vagi. Zbroj tako dobivenih masa iznosi $0,8661 \mathrm{~g}$, što je pogreška vaganja od $0,45 \%$ u odnosu na početno vaganje. Razlika se pripisuje zaokruživanju mase prilikom vaganja velikog broja ispitaka. Raspodjela mase po pojedinoj kategoriji prikazana je na slici 4. Granule i fragmenti imaju najveći udio u masi, zatim peleti, a manji udio imaju filmovi, pjenasti ispitci i filamenti. Vidljivo je da maseni udjeli ne odgovaraju brojčanim udjelima pojedine kategorije, što je posljedica različite gustoće i debljine ispitaka iz pojedine kategorije. Tako, primjerice, granule čine $36,57 \%$ mase, a brojčano svega $14,66 \%$, dok pjenasti ispitci zbog niske gustoće čine svega $2,15 \%$ mase u odnosu na brojčani udio od $11,21 \%$.

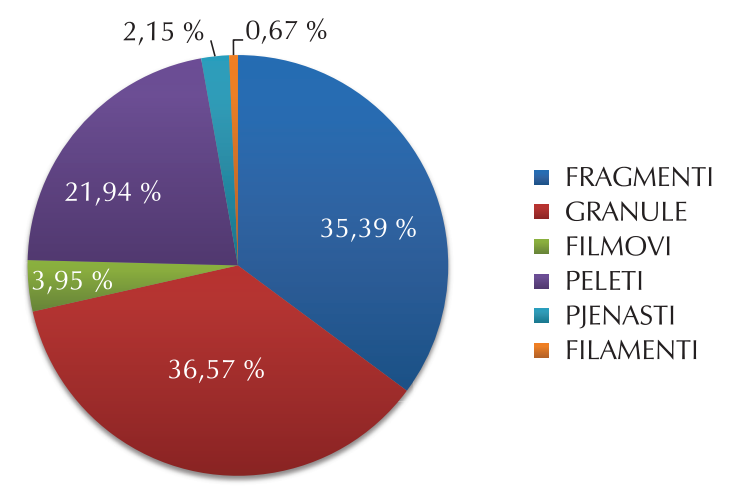

Slika 4 - Maseni udjeli pojedine kategorije mikroplastičnog otpada iz sedimenta plaže Prapratno ${ }^{10}$

Fig. 4 -Mass content of each category of microplastic waste from Prapratno Beach sediment ${ }^{10}$ 
Obojanost ispitaka prikazana je na slici 5, dok je prozirnost/neprozirnost prikazana na slici 6 . $U$ uzorku iz sedimenta plaže Prapratno prisutne su gotovo sve boje, a udjelom dominiraju ispitci bijele boje. Što se tiče prozirnosti, oko $90 \%$ ispitaka je neprozirno što odgovara brojčanoj raspodjeli po kategorijama (slika 2), gdje nešto više od $10 \%$ otpada na filmove koji su jedini prozirni zbog vrlo male debljine.

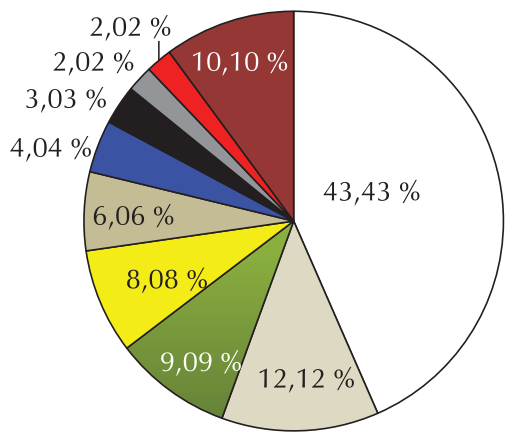

$\square$ BIJELO

$\square$ BISTRO-KREM

$\square$ ZELENO

$\square \check{Z} U T O$

$\square B E \check{~}$

- PLAVO

- CRNO

$\square$ SIVO

- CRVENO

- SMEĐE

Slika 5 - Obojanost ispitaka (brojčani udjeli) iz sedimenta plaže Prapratno $^{10}$

Fig. 5 - Colour of microplastic specimens (in percent) from Prapratno Beach sediment ${ }^{10}$

Primjenom Digimizer programa određena je maksimalna dimenzija svakog ispitka kako bi se ispitak mogao svrstati u kategorije mikroplastičnog otpada prema veličini, a to su mala mikroplastika, SMP (engl. small microplastic), velika mikroplastika, LMP (engl. large microplastic) ili tzv. mezootpad (engl. mezzo litter). Ispitci s maksimalnom dimenzi-

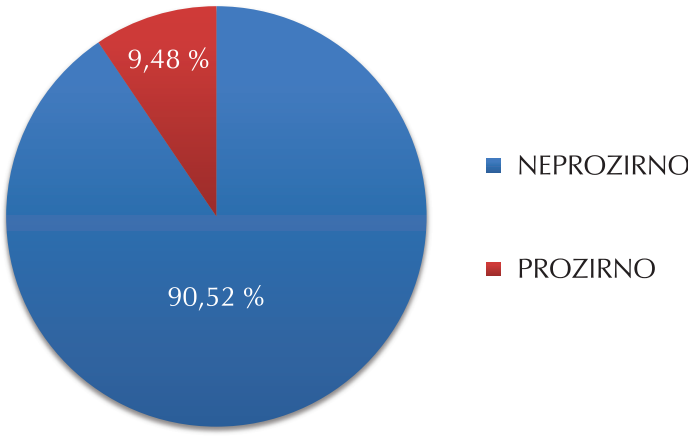

Slika 6 - Brojčani udjeli prozirnih i neprozirnih ispitaka iz sedimenta plaže Prapratno ${ }^{10}$

Fig. 6 - Numerical content of transparent and opaque specimens from Prapratno Beach sediment ${ }^{10}$

jom $20 \mathrm{~mm}-1 \mathrm{~mm}$ spadaju u SMP, ispitci s maksimalnom dimenzijom 1 - $5 \mathrm{~mm}$ spadaju u LMP, a oni s maksimalnom dimenzijom 5 - $20 \mathrm{~mm}$ spadaju u mezootpad. Ispitcima je istodobno s određivanjem maksimalne dimenzije izračunata i površina $\mathrm{u} \mathrm{mm}^{2}$. Primjer obrade ispitka primjenom Digimizer programa prikazan je na slici 7.

Rezultati pokazuju da od 116 ispitaka njih 61 ili 52,59\% ima maksimalnu dimenziju u području $1-5 \mathrm{~mm}$ i spadaju u LMP, dok njih 55 ili 47,4 \% ima maksimalnu dimenziju u području $5-20 \mathrm{~mm}$ i spadaju u mezootpad. Niti jedan ispitak nema maksimalnu dimenziju u području $20 \mathrm{~mm}-1$ $\mathrm{mm}$ te sukladno tome nema ispitaka koji spadaju u SMP. Raspodjela ispitaka s maksimalom dimenzijom u području $1-5 \mathrm{~mm}$ prikazana je na slici 8 , dok je na slici 9 prikazana raspodjela ispitaka s maksimalnim dimenzijama u području $5-20 \mathrm{~mm}$.

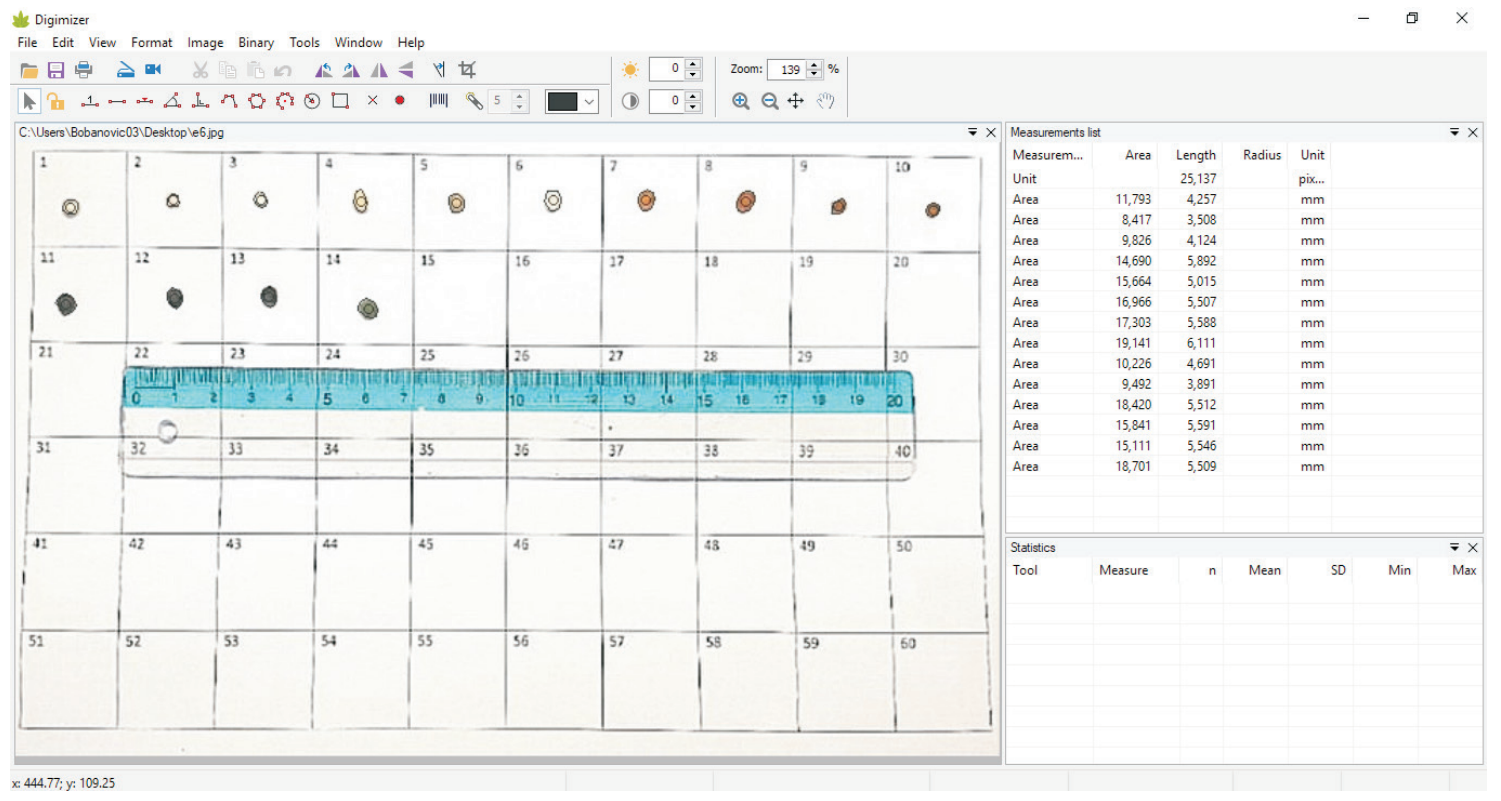

Slika 7 - Primjer obrade ispitka primjenom programa Digimizer

Fig. 7 - Example of sample processing using Digimizer software 


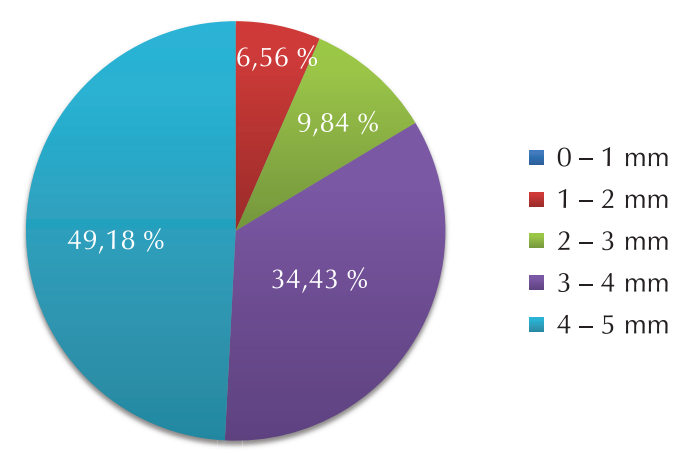

Slika 8 - Raspodjela ispitaka s maksimalom dimenzijom u području 1 - $5 \mathrm{~mm}$

Fig. 8 - Distribution of specimens with maximum dimension in the range of $1-5 \mathrm{~mm}$

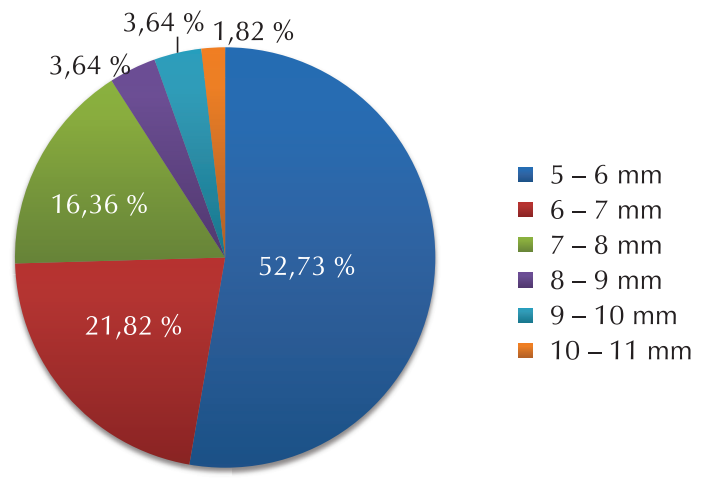

Slika 9 - Raspodjela ispitaka s maksimalom dimenzijom u području 5 - $20 \mathrm{~mm}$

Fig. 9 - Distribution of specimens with maximum dimension in the range of $5-20 \mathrm{~mm}$

Analizom raspodjele veličina može se zaključiti da prevladavaju ispitci s maksimalnom dimenzijom u području $3-8 \mathrm{~mm}$. Rezultati pokazuju da u uzorku, unatoč prosija- vanju na sitima od $4 \mathrm{~mm}$ i $1 \mathrm{~mm}$, postoji $47,41 \%$ ispitaka s maksimalnom dimenzijom većom od $5 \mathrm{~mm}$ i da time spadaju u mezootpad. Ti rezultati vezani su za nepravilan, izduženi oblik ispitaka i evidentno je da su takvi ispitci prošli okomito kroz sito od $4 \mathrm{~mm}$.

Ispitcima je određena i površina u $\mathrm{mm}^{2}$. Ukupna površina uzorka iznosi $1262,59 \mathrm{~mm}^{2}$. Udjeli pojedine kategorije u ukupnoj površini prikazani su na slici 10. Rezultati su slični brojčanom udjelu kategorija (slika 3) budući da su ispitci uglavnom u uskom području maksimalnih dimenzija, a time i površina, pa njihov brojčani udio odgovara njihovom udjelu u ukupnoj površini uzorka.

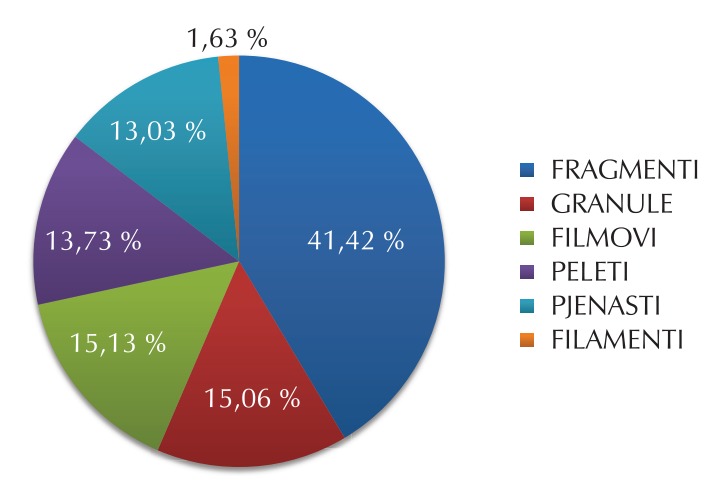

Slika 10 - Udjeli pojedine kategorije mikroplastičnog otpada iz sedimenta plaže Prapratno u ukupnoj površini uzorka

Fig. 10 - Content of each category of microplastic waste from Prapratno Beach sediment in total sample area

\subsection{Identifikacija mikroplastike primjenom infracrvene spektroskopije}

Identifikacija plastike od koje je izrađen otpad iz sedimenta plaže Prapratno provedena je infracrvenom spektroskopijom. Zbog neprozirnosti ispitaka za infracrvenu spektroskopiju, spektri su dobiveni primjenom HATR tehnike i ZnSe

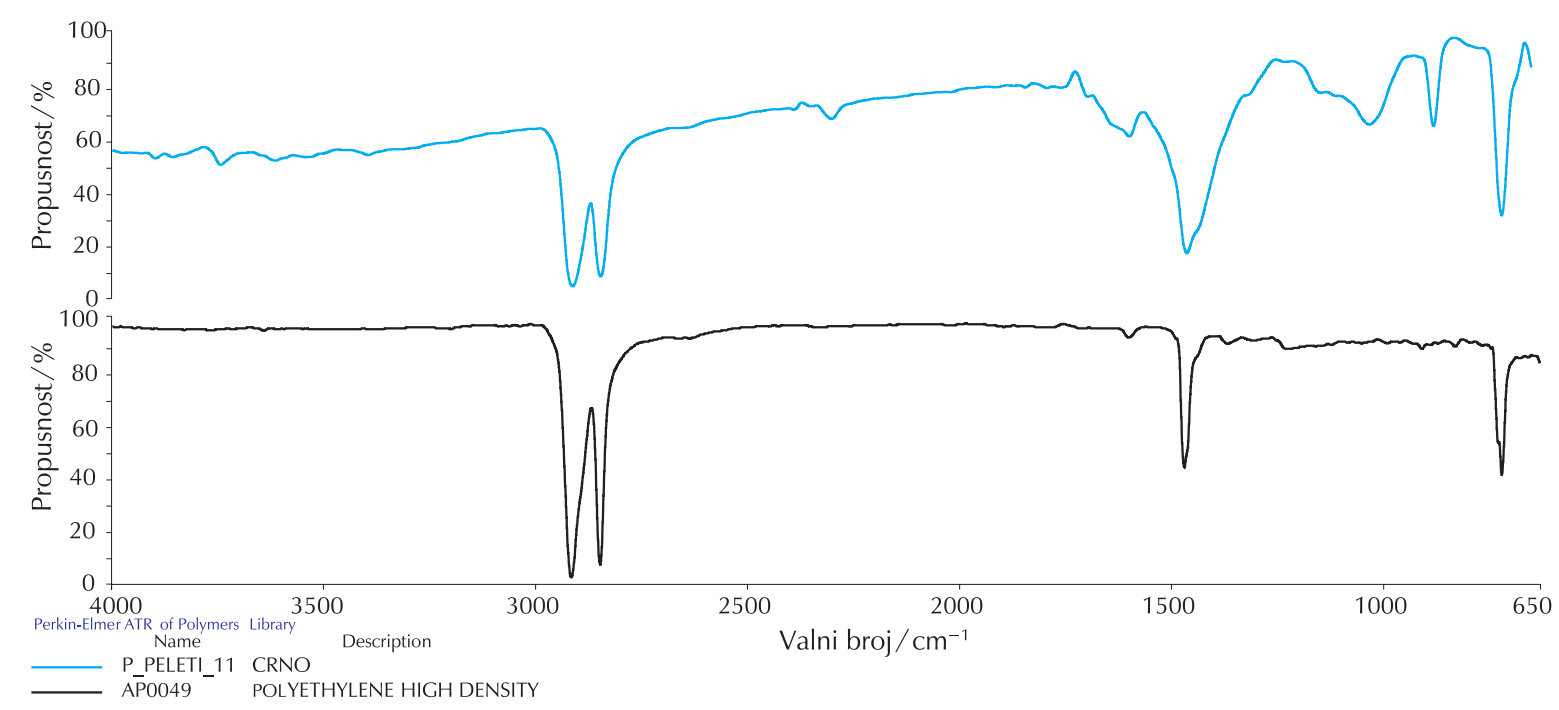

Slika 11 - Usporedba IR spektra ispitka peleta sa spektrom iz baze podataka ${ }^{10}$

Fig. 11 - Comparison of the IR spectrum of a pellet sample with the spectrum from a database ${ }^{10}$ 


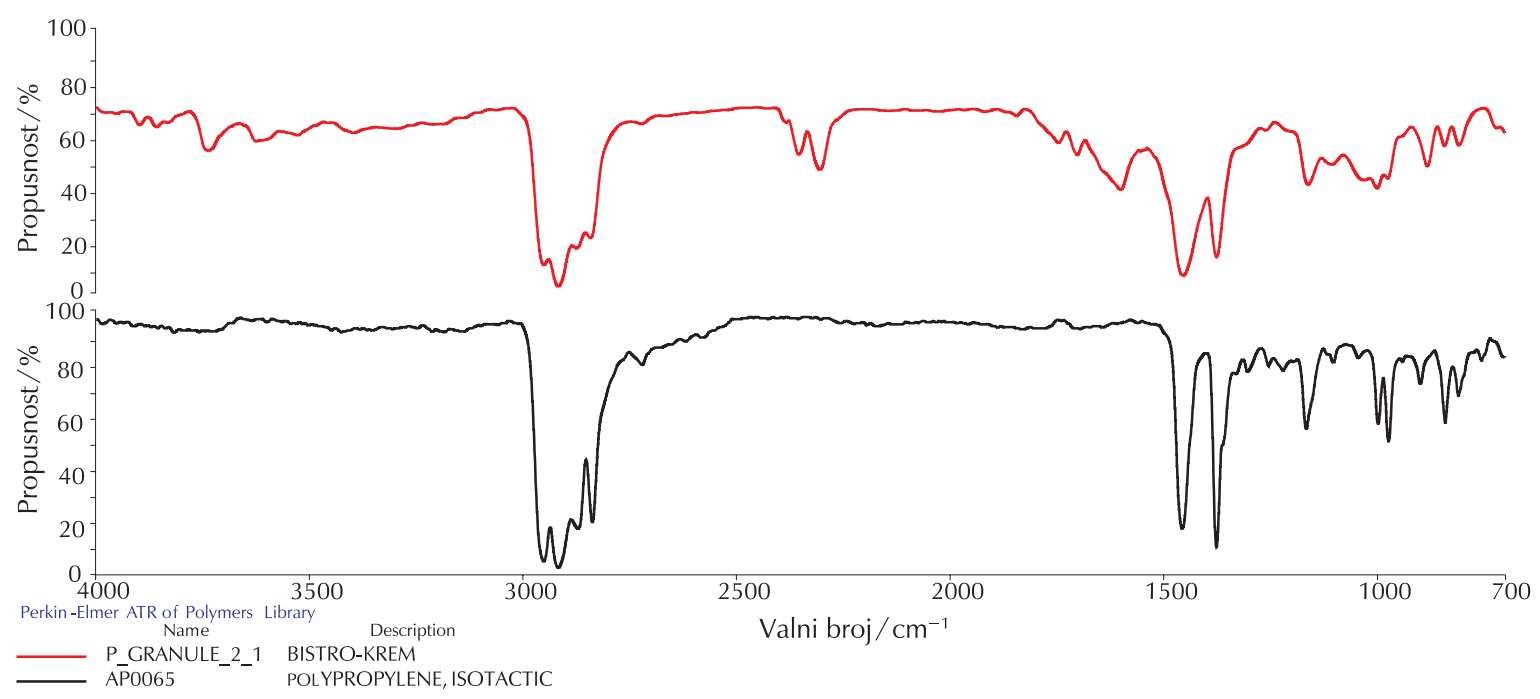

Slika 12 - Usporedba IR spektra ispitka granule sa spektrom iz baze podataka ${ }^{10}$

Fig. 12 - Comparison of the IR spectrum of a granule sample with the spectrum from a database ${ }^{10}$

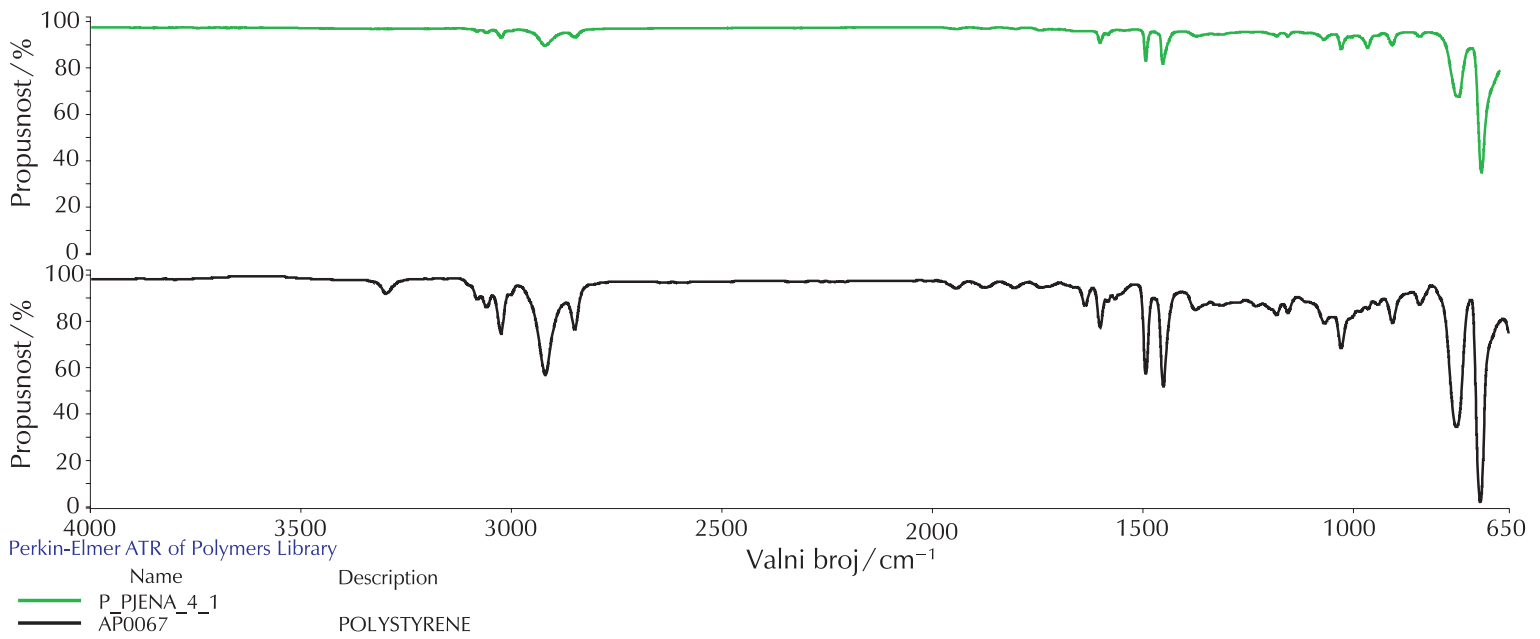

Slika 13 - Usporedba IR spektra pjenastog ispitka sa spektrom iz baze podataka ${ }^{10}$

Fig. 13 - Comparison of the IR spectrum of a foam sample with the spectrum from a database ${ }^{10}$

$\left(45^{\circ}\right)$ kristala. Svi ispitci bili su dovoljno velikih dimenzija za analizu ovom metodom. Ipak, neki dobiveni spektri su zbog male dimenzije nekih ispitaka bili nešto slabijeg intenziteta, a kod nekih ispitaka dobiven je značajniji šum. Spektrima je programski korigirana bazna linija, korigiran šum te provedena normalizacija. Primjeri tako obrađenih spektara prikazani su na slikama 11 - 13 za tri vrste plastike nađene u uzorku. Spektri svakog ispitka uspoređeni su sa spektrima u bazi podataka, a vrsta polimera i njihov udio u mikroplastičnom otpadu prikazani su na slici 14

Rezultati IR analize pokazuju da se uzorak s plaže Pratpratno sastoji od polietilena $(82,46 \%)$, polistirena $(11,40 \%)$ i polipropilena $(6,14 \%)$.

Rezultati su očekivani budući da su upravo polietilen (PE), polistiren (PS) i polipropilen (PP) najviše upotrebljavani

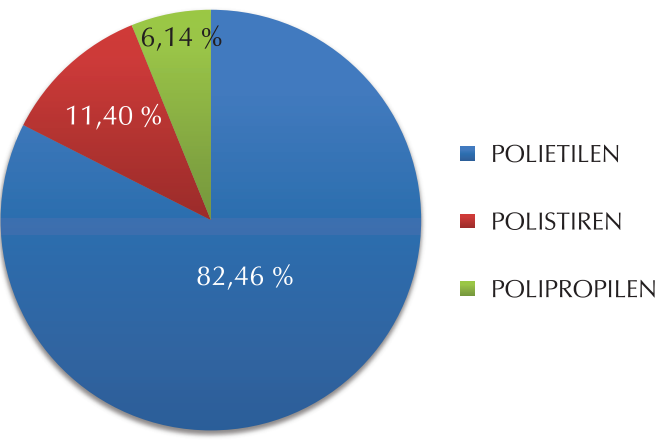

Slika 14 - Vrsta polimera i njihov udio u mikroplastičnom otpadu iz sedimenta plaže Prapratno ${ }^{10}$

Fig. 14 - Type and content of polymers in the microplastic waste from Prapratno Beach sediment ${ }^{10}$ 
polimeri u području plastične ambalaže. Ambalaža ima najkraći uporabni vijek i stoga stvara najveću količinu plastičnog otpada, a rezultati ukazuju i na to da se plastična ambalaža od PE-a, PS-a i PP-a i dalje odbacuje u okoliš umjesto da se njom gospodari u skladu sa Zakonom o održivom gospodarenju otpadom i hijerarhijom zbrinjavanja otpada. ${ }^{11}$ Nije pronađen niti jedan ispitak koji odgovara poli(etilen-tereftalatu) (PET) koji se također upotrebljava u znatnim količinama za izradu plastične ambalaže za piće. No, za razliku od PE-a, PS-a i PP-a, PET je u sustavu povratne ambalaže. Rezultat i učinkovitost te mjere za smanjenje količine otpada u okolišu je vidljiv i na primjeru mikroplastičnog otpada iz sedimenta plaže Prapratno.

\section{Zaključak}

Mikroplastični otpad iz sedimenta plaže Prapratno sastoji se od 116 uzoraka, a po obliku se može razvrstati u 6 kategorija. Brojčano su fragmenti najzastupljenija kategorija mikroplastičnog otpada, granule, filmovi, peleti i pjenasti ispitci zastupljeni su u približno istom broju, dok su filamenti najmanje zastupljena kategorija. Najvažnije kategorije po masi su granule i fragmenti, zatim peleti, dok manji udio zauzimaju filmovi, pjenasti ispitci i filamenti. Maseni udjeli ne odgovaraju brojčanim udjelima pojedine kategorije, što je posljedica različite gustoće i debljine ispitaka iz pojedine kategorije. Ispitci su obojani gotovo svim osnovnim bojama, a 90,52 \% ih je neprozirno. Maksimalnu dimenziju u području $1-5 \mathrm{~mm}$ ima $52,59 \%$ ispitaka i time spadaju u LMP, dok njih 47,41\% ima maksimalnu dimenziju u području 5 - 20 mm i time spadaju u tzv. mezootpad. Identifikacija primjenom infracrvene spektroskopije pokazala je da se mikroplastični otpad s plaže Prapratno sastoji od polietilena $(82,46 \%)$, polistirena $(11,40 \%)$ i polipropilena $(6,14 \%)$, polimera koji se najviše upotrebljavaju za izradu plastične ambalaže.

\section{Literatura \\ References}

1. URL: http://struna.ihjj.hr/naziv/plastika/6993/\#naziv (3. 10. 2019.).

2. URL: https://www.plasticseurope.org/application/files/6315/4510/9658/Plastics_the_facts_2018_AF_web.pdf (3. 10. 2019.).

3. C. Arthur, J. Baker, H. Bamford, Proceedings of the International Research Workshop on the Occurrence, Effects, and Fate of Microplastic, Marine Debris, September 9-11, NOAA Technical Memorandum NOS-OR\&R30. (2008).

4. URL: https://ec.europa.eu/info/sites/info/files/research and innovation/groups/sam/ec_rtd_sam-mnp-opinion_04立019. pdf (3. 10. 2019.).

5. S. L. Wright, R. C.Thompson, T. S. Galloway, Environ. Pollut. 178 (2013) 483-492, doi: https://doi.org/10.1016/j. envpol.2013.02.031.

6. A. Bakir, S. J. Rowland, R. C. Thompson, Estuar. Coast. Shelf. Sci. 140 (2014) 14-21, doi: https://doi.org/10.1016/j. ecss.2014.01.004.

7. M. Cole, P. Lindeque, C. Halsband, T. S. Galloway, Mar. Pollut. Bull. 62 (2011) 2588-2597, doi: https://doi.org/10.1016/j. marpolbul.2011.09.025.

8. F. Galgani, G. Hanke, S. Werner, L. Oosterbaan, P. Nilsson, D. Fleet, S. Kinsey, R. C. Thompson, J. Van Franeker, T. Vlachogianni, M. Scoullos, J. Mira Veiga, A. Palatinus, M. Matiddi, T. Maes, S. Korpinen, A. Budziak, H. Leslie, J. Gago, G. Liebezeit, Guidance on Monitoring of Marine Litter in European Seas. MSFD Technical Subgroup on Marine Litter (TSG-ML), 2013.

9. URL: https://mcc.jrc.ec.europa.eu/documents/201702074014.pdf (3. 10. 2019.).

10. A. Bobanović, Karakterizacija mikroplastičnog otpada iz sedimenta hrvatskih plaža, Završni rad, Kemijsko-tehnološki fakultet, Split, 2019.

11. URL: https://www.zakon.hr/z/657/Zakon-o-odr\%C5\%BEivom-gospodarenju-otpadom (6. 10. 2019.). 


\section{EXTENDED ABSTRACT}

\section{Characterization of Microplastics in Prapratno Beach Sediment} Matko Erceg, ${ }^{a^{*}}$ Pero Tutman, ${ }^{\mathrm{b}}$ Dubravka Bojanić Varezić, ${ }^{\mathrm{b}}$ and Anđela Bobanovića

Microplastics represent a major problem in the marine and coastal environment. In this work, microplastics from the sediment of Prapratno beach on the Pelješac Peninsula (Croatia) were analysed. Sampling and laboratory separation were performed according to the DeFishGear protocol (Derelict Fishing Gear Management System in the Adriatic Region). The microplastic waste from Prapratno beach sediment consisted of 116 specimens, which could be classified into 6 micro litter categories according to EU TG ML Master List (Fig. 1). Fragments were found to be the predominant category of microplastic waste from the sediment of Prapratno beach, followed by granules, films, pellets and foams, which were present in approximately the same number, while filaments were the least represented category (Fig. 2). The most important categories by mass were granules and fragments, followed by pellets, while films, foams and filaments made up a very small content of the total sample mass (Fig. 3). The numerical contents (Fig. 4), did not correspond to the mass contents (Fig. 3) of individual categories due to the different densities and thicknesses of the specimens in each category. Almost all the base colours were present in the analysed samples (Fig. 5), while $90.52 \%$ of specimens were opaque (Fig. 6). The maximum dimension and surface area of each specimen was determined by Digimizer Image Analysis Software. Maximum dimensions in the range of 1-5 mm were observed in $52.59 \%$ of the specimens, thus belonging to large microplastics (LMP), while $47.41 \%$ of the specimens had maximum dimensions in the range of 5-20 mm, thus belonging to so-called mezzo litter. The distribution of specimen dimensions within LMP is shown in Fig. 8, and within mezzo litter in Fig. 9. The fraction of each category in the total sample surface area is shown in Fig. 10. These results are similar to the numerical fractions of categories, since the samples were generally in the narrow range of maximum dimensions, and thus their numerical fractions corresponded to their fraction in the total surface of the sample. Identification of plastic material was performed by infrared spectroscopy, HATR technique. The obtained spectra were compared with the spectra in the database (Fig. 11-13). The results showed (Fig. 14) that the microplastic waste from Prapratno beach was made of polyethylene $(82.46 \%)$, polystyrene $(11.40 \%)$ and polypropylene $(6.14 \%)$. These polymers came from plastic packaging since polyethylene, polystyrene and polypropylene are the most used polymers for plastic packaging.

\section{Keywords}

Microplastics, waste categories, sediment, infrared spectroscopy, Prapratno

a Faculty of Chemistry and Technology

Ruđera Boškovića 35

21000 Split, Croatia

b Institute of Oceanography and Fisheries

Setalište Ivana Meštrovića 63

21000 Split, Croatia
Original scientific paper Received December 4, 2019 Accepted January 17, 2020 